\title{
Revista \\ Brasileira \\ de Enfermagem \\ REBEn \\ Concepções da equipe de enfermagem sobre a exposição a riscos físicos e químicos no ambiente hospitalar
}

PESQUISA

\author{
Conceptions of nursing staff about the exposure to physical and chemical risks in hospital environment
}

Concepciones del personal de enfermería sobre exposición a riesgos físicos y químicos en el ambiente hospitalario

\author{
Ethiele Sulzbacher', Rosane Teresinha Fontana' \\ ' Universidade Regional Integrada do Alto Uruguai e das Missões, Campus Santo Ângelo, \\ Curso de Enfermagem. Santo Ângelo-RS, Brasil.
}

Submissão: 22-08-2011 Aprovação: 23-02-2013

\section{RESUMO}

Este estudo teve como objetivo identificar como a equipe de enfermagem percebe os riscos físicos e químicos a que está exposta no ambiente hospitalar. Trata-se de um estudo descritivo, baseado em uma pesquisa de campo exploratória, de origem quantitativa. Os dados foram coletados mediante um questionário aplicado a 33 profissionais da equipe de enfermagem de um hospital geral da região noroeste do estado do Rio Grande do Sul, no primeiro semestre de 2011 e foram analisados por meio da estatística descritiva. Os trabalhadores perceberam os riscos físicos e químicos a que estão expostos e referiram reconhecê-los, porém, à análise das respostas, identificou-se conhecimento deficiente sobre a concepção científica do risco físico. A educação permanente em saúde pode ser uma estratégia para atualização dos trabalhadores sobre os riscos ocupacionais.

Descritores: Saúde do Trabalhador; Riscos Ocupacionais; Enfermagem.

\section{ABSTRACT}

This study aimed to identify how the nursing team realizes the chemical and physical risks to which it is exposed in the hospital environment. This is a descriptive study, based on an exploratory field research, of quantitative source. Data were collected through a questionnaire administered to 33 professional nursing staff of a general hospital in the northwestern region of the state of Rio Grande do Sul, in the first half of 2011 and were analyzed using descriptive statistics. The workers noticed chemical and physical risks they are exposed and reported to recognize them, however, after the analysis of the responses, we identified knowledge deficit about the scientific conception of physical risk. The continuing health education can be a strategy to update workers on occupational risks.

Key words: Occupational Health; Occupational Risks; Nursing.

\section{RESUMEN}

Este estudio tuvo como objetivo identificar cómo el equipo de enfermería se da cuenta de los riesgos químicos y físicos a los que está expuesto en el ambiente hospitalario. Se trata de un estudio descriptivo, basado en una investigación exploratoria de campo, de origen cuantitativa. Los datos fueron recolectados a través de un cuestionario aplicado a 33 trabajadoras de enfermería de un hospital general en la región noroeste del estado de Rio Grande do Sul, en el primer semestre de 2011, analizados mediante estadística descriptiva. Los trabajadores perciben los riesgos químicos y físicos a que están expuestos e informan reconocerlos; sin embargo, en el análisis de las respuestas, hemos identificado déficit de conocimiento sobre la concepción científica del riesgo físico. La educación permanente en salud puede ser una estrategia para actualizar los trabajadores sobre los riesgos laborales.

Palabras clave: Salud Ocupacional; Riesgos Ocupacionales; Enfermería. 


\section{INTRODUÇÃO}

De acordo com o código de ética dos profissionais de enfermagem, o trabalhador deve atuar de modo a contribuir para a resolução das necessidades de saúde dos usuários, mediante ações livres de negligência, imperícia e/ou imprudência, assim como desenvolver suas atividades sob condições seguras ${ }^{(1)}$.

Sendo assim, é oportuno discutir sobre a criação de ambiências saudáveis que apontem para a prevenção de agravos ao trabalhador e sobre estratégias que envolvam a atenção integral à saúde, a articulação intra e intersetorial, a análise da situação de saúde desses sujeitos, a participação popular e, entre outros, o apoio ao desenvolvimento de estudos ${ }^{(2)}$. Esta pesquisa se alicerça no pressuposto de que, estando a equipe de enfermagem intimamente em contato com os usuários dos serviços de saúde, tornam-se sujeitos suscetíveis ao sofrimento e adoecimento decorrentes, especialmente, da exposição aos riscos ocupacionais, gerados por conta das condições desfavoráveis do ambiente de trabalho.

Os ambientes hospitalares concentram inúmeros agentes e/ou fatores de risco, alguns deles ocultos ou desconhecidos, mas que podem causar danos à saúde do trabalhador. Observam-se, em muitos cenários, deficientes medidas acerca da gestão de riscos ocupacionais e, diante da magnitude dos problemas consequentes da falta de biossegurança no campo de trabalho da enfermagem, a exposição aos agentes de risco é uma realidade que necessita de evidências em bases estatísticas sólidas que forneçam elementos para a criação de condições favoráveis ao trabalho e possibilitem práticas de autocuidado $^{(3)}$.

Os riscos ocupacionais referem-se à condições, situações, procedimentos, condutas ou eventos que podem implicar em efeito negativo, causando dano ao usuário do serviço, ao trabalhador, ao ambiente e ao estabelecimento ${ }^{(4)}$.

Sabe-se que o trabalhador da enfermagem, mesmo intimamente ligado ao processo terapêutico do cuidado do usuário, não raramente negligencia o autocuidado, naturalizando os riscos. O cuidado de si envolve "uma atitude ligada ao exercício da política, a certo modo de encarar as coisas, de estar no mundo, de relacionar-se com o outro e consigo mesmo; de agir de si para consigo, de modificar-se, purificar-se, se transformar, e transfigurar-se ${ }^{\prime \prime(5)}$. Está vinculado à ética, à estética, ao fazer o bem a si mesmo e ao viver saudável.

Sendo assim, refletir sobre a saúde do trabalhador torna-se indispensável, no processo de produção de saúde. Essa atenção está prevista na lei no $8080 / 90$, no artigo $6^{\circ}$, parágrafo $3^{\circ}$, que se refere à obrigatoriedade de atividades que se destinem, por meio de ações de vigilância epidemiológica e sanitária, à promoção e proteção da saúde dos trabalhadores e que visem à recuperação e reabilitação dos trabalhadores submetidos aos riscos e agravos advindos das condições de trabalho ${ }^{(6)}$.

Segundo a Norma Regulamentadora (NR) nº9, do Ministério do Trabalho e Emprego (BR), que estabelece o Programa de Prevenção de Riscos Ambientais, caracteriza-se agentes biológicos as bactérias, os fungos, os bacilos, os parasitas, os protozoários, os vírus, entre outros; os agentes físicos são as diversas formas de energia a que possam estar expostos os trabalhadores, tais como ruídos, vibrações, pressões anormais, temperaturas extremas, radiações ionizantes e não ionizantes, bem como o infrassom e o ultrassom. Os agentes químicos podem ser considerados as substâncias, compostos ou produtos que possam penetrar no organismo pela via respiratória, nas formas de poeira, fumo, névoa, neblina, gás ou vapor, ou que pela natureza da atividade de exposição, possam ter contato ou ser absorvidos pelo organismo através da pele ou ingestão ${ }^{(7)}$.

A Organização Mundial de Saúde acrescenta, ainda, os agentes ergonômicos decorrentes de má postura, inadequação do mobiliário e outros responsáveis por distúrbios osteomusculares; os agentes psicossociais advindos de relações conflituosas, monotonia, ritmo excessivo, entre outros. Já os agentes mecânicos e de acidentes são aqueles ligados à falta de proteção do trabalhador, aparelhamento inadequado, arranjo físico, ordem e limpeza do ambiente de trabalho e sinalização deficientes ${ }^{(8)}$,entre outros.

Isto posto, há muito por conhecer e discutir a respeito da origem, do controle e da prevenção dos riscos ocupacionais, porém pela escassa produção científica e magnitude do fenômeno à saúde humana optou-se pelo estudo dos riscos físicos e químicos no trabalho da enfermagem. Estes últimos apresentam significativa dimensão pela inclusão de substâncias novas no mercado, por conseguinte, no espaço de trabalho e pela possibilidade de adoecimento em virtude da exposição constante do trabalhador a substâncias de expressiva toxicidade.

No tocante aos riscos físicos, o trabalhador da enfermagem convive com muitos agentes de desconforto, sendo que a exposição a extremos de temperatura ${ }^{(9)}$, desperta preocupação, tendo em vista o desarranjo climático e ambiental que assola o país, favorecendo ondas de calor que desidratam e provocam mal estar, visto que, em muitos cenários, ainda é inexistente a climatização artificial. Além deste, os ruídos tecnológicos, presentes no cotidiano do cuidado, também são agentes que geram incômodo e estresse ao trabalhador exposto, entre outros ${ }^{(10)}$.

Pretende-se estudar os riscos físicos e químicos, considerando a relativa escassez de pesquisas sobre o tema, e pelas observações feitas no cotidiano das práticas em que os trabalhadores da equipe de enfermagem tendem a banalizá-los, tornando estes agentes ocupacionais fatores potenciais para o adoecimento. Acredita-se que agentes físicos e químicos capazes de causar agravos passem despercebidos pela equipe de enfermagem, fazendo com que ela habitue-se a conviver com os mesmos na sua rotina de trabalho, desconsiderando danos e subnotificando acidentes com estes agentes.

Alguns resultados investigativos comprovam o insuficiente conhecimento da equipe de enfermagem quanto aos fatores de risco químico e físico a que estão submetidos e sua escassa discussão na literatura ${ }^{(3,11)}$. Tratando-se dos riscos físicos, poucos profissionais conseguem identificá-los e muitas vezes os confundem. Um reduzido número de profissionais associa-os de acordo com seus agentes, ou seja, a temperaturas extremas, ruídos, vibração, radiação e umidade ${ }^{(12)}$, o que reforça a relevância desse estudo.

Partindo da hipótese de que a equipe de enfermagem não reconhece os riscos ocupacionais em toda a dimensão 
necessária que os mesmos exigem para a prevenção e controle, pretende-se investigar como esta equipe percebe, em especial, os riscos químicos e físicos que, muitas vezes, emergem de forma imperceptível, de modo a buscar elementos para que gestores e trabalhadores possam refletir sobre os mesmos e construir estratégias de prevenção aos agravos causados pela sua exposição, contribuindo para a saúde do trabalhador. Assim, o objetivo geral deste estudo foi identificar como os membros da equipe de enfermagem percebem os riscos físicos e químicos a que estão expostos no ambiente hospitalar.

\section{MATERIAIS E MÉTODOS}

Trata-se de um estudo descritivo, exploratório, com abordagem quantitativa, realizado no primeiro semestre de 2011, com trabalhadores da equipe de enfermagem de um hospital geral da região noroeste do estado do Rio Grande do Sul. O referido hospital possui 116 leitos e presta serviços de atendimento clínico adulto e pediátrico, cirúrgico, ambulatorial, psiquiátrico e de obstetrícia.

Participaram da pesquisa 33 trabalhadores, atuantes nos turnos da manhã, tarde e noite de um total de 78 sujeitos da equipe de enfermagem. Foram definidos os seguintes critérios de inclusão no estudo: ser enfermeiro e/ou técnico de enfermagem, integrar o quadro funcional da instituição e aceitar participar. Foram excluídos da pesquisa os trabalhadores, que, no momento da pesquisa encontrava-se em férias e/ou afastados, o que correspondeu a oito trabalhadores.

Os dados foram coletados, por meio de um questionário autoaplicável, elaborado pelos pesquisadores, composto por dez questões. As perguntas versaram sobre a identificação e reconhecimento dos riscos físicos e químicos pelos trabalhadores, o uso de Equipamento de Proteção Individual (EPI) e o adoecimento decorrente da exposição a estes agentes. O formulário foi entregue aos sujeitos nas dependências do hospital e agendado, junto a eles, um horário e um dia, de melhor conveniência, para o recolhimento do instrumento. A análise dos dados teve como suporte a estatística descritiva, utilizando-se a distribuição da frequência.

O estudo foi aprovado pelo Comitê de Ética em Pesquisa da Universidade Regional Integrada do Alto Uruguai e das Missões e recebeu o $n^{\circ}$ 0098-PPH/10, em cumprimento as orientações das recomendações legais que protegem a pesquisa envolvendo seres humanos ${ }^{(13)}$. Todos os participantes da pesquisa assinaram um Termo de Consentimento Livre e Esclarecido e ao gestor da instituição foi encaminhado um Termo de Ciência, o qual foi assinado, autorizado-o.

\section{RESULTADOS E DISCUSSÃO}

\section{Caracterização dos sujeitos}

Aceitaram participar do estudo 33 sujeitos, de um total de 78 trabalhadores da equipe de enfermagem. Entre os sujeitos, $6 \%$ eram enfermeiros e $94 \%$ técnicos em enfermagem; $67 \%$ eram do sexo feminino, $45 \%$ casados e $100 \%$ trabalhavam 36 horas semanais na instituição. Não houve a intenção de associar variáveis.

\section{O reconhecimento dos Riscos}

Questionados sobre o reconhecimento do principal fator prejudicial no trabalho, apenas $3 \%$ dos sujeitos reconheceram os riscos químicos e $6 \%$ os riscos físicos. Os riscos biológicos e ergonômicos foram os mais lembrados, em $42 \%$ das respostas, salientando-se que foi citado mais de um risco pelo mesmo sujeito. Estudo realizado em um hospital universitário junto a 296 trabalhadores da enfermagem verificou que, semelhante a esta investigação, os problemas observados com maior frequência no ambiente de trabalho, envolvendo os riscos ocupacionais, foram, respectivamente, a exposição aos riscos biológicos, seguidos dos riscos físicos, ergonômicos e químicos ${ }^{(14)}$.

É válido referir que 3\% acreditam não haver nenhum risco para a saúde em seu ambiente de trabalho e muitos não responderam, analogamente a um estudo que demonstrou que o risco químico foi percebido por somente um terço dos profissionais da equipe de enfermagem ${ }^{(14)}$.

\section{$O$ reconhecimento do risco físico}

Questionados sobre o risco físico, singular e especificamente, $85 \%$ dos respondentes acreditam estar expostos ao mesmo. Porém a análise das respostas demonstrou que há um conhecimento deficiente acerca desta categoria de risco, considerando que o classificaram inadequadamente, atribuindo risco físico a situações que abalam a integridade do corpo físico/orgânico, desvinculando-o de agentes como ruído, vibração, radiação ionizante e não ionizante, temperaturas extremas (frio e calor), pressão atmosférica anormal, e outros ${ }^{(7,9)}$.

Mais de um terço dos sujeitos (36\%) atribuiu o risco físico ao risco biológico, associando-o aos materiais perfurocortantes, a exposição a material biológico, como sangue, fluídos e secreções; $27 \%$ associaram-no ao risco ergonômico, como 'erguer' peso, empurrar macas e cadeiras de roda e $21 \%$ atribuíram-no ao risco psicossocial, como o risco de agressão por parte de pacientes e acompanhantes. Os sujeitos que não responderam corresponderam a $7 \%$.

Apenas 3\% classificaram adequadamente a resposta ao risco físico, conforme sua concepção científica, citando fatores como mudança de clima, temperatura e ruídos. É importante salientar que mais de uma classificação de risco foi atribuída por $6 \%$ dos sujeitos, o que reforça que há incompreensão ou desconhecimento da conceituação e classificação de risco físico, semelhante a outros estudos ${ }^{(12,15)}$, que demonstram o fato deste risco ser pouco identificado pelos trabalhadores da enfermagem.

Ao serem abordados sobre as condições de iluminação, umidade, frio, calor, ventilação e exposição à radiação no cotidiano do seu trabalho, a maioria dos sujeitos reconheceu a exposição a esses agentes e avaliaram-nos como bom. Apenas uma minoria reconheceu-os como péssimo, reforçando, ainda mais a contradição das respostas e, conseqüentemente o reconhecimento deficiente do agente físico como possível causador de agravos.

Não foi intenção do estudo, medir a iluminação, a temperatura, a umidade ou o ruído do ambiente, porém se observou 
que em algumas unidades do hospital, lâmpadas estavam queimadas ou com capacidade de iluminação diminuída. Não há climatizadores em nenhum ambiente de cuidado, o que facilita extremos de temperatura, especialmente na região estudada, noroeste do Rio Grande do Sul, que oscila entre frio e calor extremos. A Norma Regulamentadora (NR) nº17 recomenda índices de temperatura efetiva entre $20^{\circ} \mathrm{C}$ e $23^{\circ} \mathrm{C}$ para proporcionar condições de conforto nos locais de trabalho ${ }^{(7)}$, o que, na região Sul, são índices difíceis de se sustentar sem o uso de climatizadores.

Estudos apontam suspeitas de doenças relacionadas à exposição constante à luz, um agente físico de significativo impacto sobre a saúde de quem trabalha por muito tempo em horário noturno. Há estudos que associam a exposição à luz aos distúrbios endócrinos, considerando que durante a noite há supressão na produção de melatonina e o trabalho constante sob a luz artificial poderia produzir tumores endócrinos, aumentando os riscos de câncer e outras doenças graves. Além disso, comparado com mulheres que nunca trabalhavam à noite, foi verificado um risco significativamente maior de fraturas naquelas que trabalhavam neste turno, embora associados com outras variáveis, e sob alguns viéses ocasionados por variáveis não controladas ${ }^{(16)}$.

A exposição à radiação ionizante não foi citada por qualquer sujeito da pesquisa, porém requer estudos específicos, visto que, inúmeras vezes, especialmente em instituições de pequeno porte, a enfermagem auxilia nas atividades de contenção, conforto e apoio às atividades do profissional técnico em radiologia quando da realização de exames no leito ${ }^{(17)}$. Tal situação é preocupante, pois os trabalhadores de saúde, em geral, ignoram os princípios básicos de proteção radiológica, além de que, normalmente, há escassez dos equipamentos de proteção individual para estas situações.

\section{O reconhecimento do risco químico}

Ao serem analisadas as respostas com relação à exposição ao risco químico no trabalho, verificou-se que 51,5\% dos sujeitos participantes reconhecem a exposição a esse risco ocupacional, sendo atribuída, pela maioria, ao contato com medicamentos e desinfetantes. Do total que reconheceu a exposição, 41\% associaram-no aos medicamentos, 23,5\% aos desinfetantes e $17,5 \%$ aos 'produtos químicos', os quais não foram exemplificados; $11 \%$ não responderam. $O$ sangue foi citado por $7 \%$ dos respondentes como associado ao agente químico, reforçando o conhecimento deficiente sobre o risco ocupacional em evidência. Esta classificação de risco ocupacional, semelhante a outro estudo ${ }^{(15)}$, foi pouco citada pelos sujeitos, embora exista uma grande variedade de produtos químicos presentes nos ambientes de atuação da equipe de enfermagem, tais como luvas de látex, detergentes e sabões, álcool, gases anestésicos, entre outros.

Mesmo reconhecendo o risco químico, é importante salientar que agentes de outras classificações de risco foram atribuídos pelos respondentes a essa categoria. Parte dos sujeitos o associou ao risco físico $(17,6 \%)$ ou ao biológico $(5,8 \%)$, o que denota um desconhecimento sobre o conceito desse risco ocupacional, cujos agentes ou fatores são substâncias químicas, sob a forma líquida, gasosa ou de partículas e poeiras minerais e vegetais, comuns nos processos de trabalho expondo o trabalhador ${ }^{(9)}$.

O hipoclorito de sódio foi um dos produtos químicos mais lembrados pelos sujeitos, em $18 \%$ das respostas. No hospital em estudo, a desinfecção química de alguns materiais é feita com esse saneante, em Centro de Material e Esterilização. O hipoclorito de sódio é corrosivo e tóxico para a saúde humana e seu vapor pode levar à irritação dos olhos, nariz, garganta e pele ${ }^{(18)}$.

Ainda quanto ao adoecimento e à associação com produtos químicos, uma pesquisa que examinou as relações entre o trabalho, o uso de produtos saneantes e uso de luvas de látex com o surgimento de asma entre os enfermeiros e outros trabalhadores da saúde europeus, verificou aumento dos riscos entre os técnicos hospitalares e entre aqueles que utilizam amônia e/ou produtos sanitários no trabalho. Tarefas como processamento de artigos, tais como a desinfecção foram fatores de risco apontados ${ }^{(19)}$.

Abordou-se, também, o uso de equipamentos de proteção individual (EPI) pelos sujeitos da equipe de enfermagem. Todos referiram utilizar algum EPI, sendo que $100 \%$ dos respondentes assinalaram luvas de procedimento; $82 \%$ relataram usar, além das luvas, máscaras e aventais e $34 \%$ acrescentaram, também, o uso de óculos. Uma pequena minoria $(3,5 \%)$ citou a touca. Esses dados não permitem generalização, pois podem ser respostas atribuídas a pessoal de unidades críticas.

Constatou-se que $12 \%$ dos sujeitos sofreram acidente de trabalho no último ano, todos com materiais perfurocortantes, notificados. Dos entrevistados, $15 \%$ referiram agravos em decorrência da sua atividade, sendo todos relacionados ao risco ocupacional ergonômico, como dores na região lombar, 'problemas' de coluna e tendinite. Merece ser destacado que nenhum sujeito mencionou os agentes físicos ou químicos como responsáveis por doenças ou acidentes ocupacionais.

Agentes químicos estão presentes no trabalho da Enfermagem e são manuseados cotidianamente durante a assistência ao paciente, na organização da área de trabalho ou na desinfecção e esterilização de materiais. Isto posto é preciso atenção à periculosidade que representa ao sujeito que o manuseia. Cabe à instituição a elaboração de um Plano de Gerenciamento de Resíduos Químicos Perigosos, que envolva desde a segregação até o tratamento e disposição final de resíduos de produtos químicos utilizados ou vencidos. Quando este Plano não está organizado adequadamente, mais facilmente é disseminado o potencial de inflamabilidade, corrosividade, reatividade e toxicidade das substâncias químicas aos trabalhadores, à comunidade e à fauna e flora(18), situação preocupante à saúde individual e coletiva.

Da mesma forma, barulhos e ruídos, causados pela conversação entre as pessoas, pelos alarmes de aparelhos, pelo uso de telefones fixos e celulares, por jato d'água da pia, especialmente em turnos movimentados, ${ }^{(20)}$ entre outros, são muitas vezes, assim como a exposição à radiação e à temperaturas extremas, naturalizados e banalizados pelo trabalhador. 


\section{CONSIDERAÇÕES FINAIS}

Os resultados encontrados neste estudo demonstram que os riscos químicos e físicos ainda são negligenciados pela equipe de enfermagem. Sendo assim, é preciso atenção à educação permanente em saúde focada na atualização de saberes acerca dos riscos ocupacionais desta natureza, considerando que, de forma direta ou indireta, estes agentes configuram um ambiente desfavorável ao cuidado saudável e seguro ao usuário do serviço e ao trabalhador, além de comprometer a qualidade de vida.

O estudo teve relevância, tendo em vista que a produção científica é escassa nesta temática, além de que evidenciou que a equipe de enfermagem pesquisada, embora perceba os riscos a que seus membros estão expostos, contradiz-se quanto à definição científica do risco físico e uma minoria dos profissionais reconheceu os riscos químicos e físicos como fator prejudicial em seu ambiente de trabalho.

Elaborar e fomentar estratégias para a inserção de temas, oficinas e conteúdos relativos a prevenção de agravos e promoção da saúde do trabalhador nos cursos técnicos e de graduação das áreas de saúde pode preparar os profissionais para o enfrentamento e gestão dos riscos ocupacionais a agregar valor a saúde ocupacional e à qualificação do trabalho.

Sugere-se a realização de outros estudos que possam explorar os riscos físicos e químicos nos ambientes de trabalho, de modo a tirá-los da invisibilidade e a sensibilizar gestores e profissionais para a prevenção de agravos e promoção da saúde do trabalhador de enfermagem.

\section{REFERÊNCIAS}

1. Conselho Federal de Enfermagem [homepage na internet]. Código de Ética dos Profissionais de Enfermagem [acesso em 13 jan 2013]. Disponível em: http://www.portalcofen.gov.br/sitenovo/node/4158.

2. Ministério da Saúde (Brasil). Portaria GM/MS nº 1.823, de 23 de agosto de 2012. Política Nacional de Saúde do Trabalhador e da Trabalhadora [portaria na internet]. Diário Oficial da União Brasília 24 ago 2012 [acesso em 20 fev 2013]. Disponível em: http://portal.saude.gov.br/ portal/saude/area.cfm?id_area $=928$.

3. Bessa MEP, Almeida MI, Araújo MFM, Silva MJ. Riscos ocupacionais do enfermeiro atuante na estratégia saúde da família. Rev Enferm 2010;18(4):644-49.

4. D'Innocenzo M., coordenador. Indicadores, auditorias, certificações. Ferramentas de qualidade para a gestão em saúde. São Paulo: Martinari; 2006.

5. Bub MBC, Medrano C, Silva CD, Wink S, Liss PE, Santos EKA. A noção de cuidado de si mesmo e o conceito de autocuidado na enfermagem. Texto Contexto Enferm 2006;15(nEsp):152-7.

6. Ministério da Saúde (Brasil). Lei no 8.080 de 19 de Setembro de 1990. Dispõe sobre as condições para a promoção, proteção e recuperação da saúde, a organização e o funcionamento dos serviços correspondentes e dá outras providências [legislação na internet]. Diário Oficial da União 20 set 1990 [acesso em 19 fev 2010]. Disponível em http://portal.saude.gov.br

7. Ministério do Trabalho (Brasil). Normas Regulamentadoras [legislação na internet]. Diário Oficial da União 1978 [acesso em 23 jan 2010]. Disponível em: http://portal. mte.gov.br/legislacao/normas-regulamentadoras-1.htm.

8. Ministério da Saúde do Brasil. Organização Pan-Americana da Saúde no Brasil. Doenças relacionadas ao trabalho: manual de procedimentos para os serviços de saúde. Brasília: Ministério da Saúde do Brasil; 2001.
9. Espindola MCG, Fontana RT. Riscos ocupacionais e mecanismos de autocuidado do trabalhador de um centro de material e esterilização. Rev Gaúcha Enferm 2012;33(1):116-23.

10. Oliveira EB, Lisboa MTL. Exposição ao ruído tecnológico em CTI: estratégias coletivas de defesa dos trabalhadores de enfermagem. Esc Anna Nery Rev Enferm 2009;13(1):24-30.

11. Xelegati R, Robazzi MLCC, Marziale MHP, Haas VJ. Riscos ocupacionais químicos identificados por enfermeiros que trabalham em ambiente hospitalar. Rev Latino-Am Enferm 2006;14(2):214-19.

12. Rezende MP, Robazzi MLCC, Secco IAO, Suazo SVV. Riscos físicos e sua identificação por auxiliares de enfermagem de hospital de ensino do estado de Minas Gerais, Brasil. Rev Enferm UFPE On Line [periódico na internet]. 2009 [acesso em 5 ago 2010];3(3):152-59. Disponível em: http://www.ufpe.br/revistaenfermagem/index.php/ revista/article/view/168/168.

13. Ministério da Saúde (Brasil). Conselho Nacional de Saúde. Resolução no 196, de 10 de outubro de 1996. Diretrizes e normas regulamentadoras de pesquisa envolvendo seres humanos. Diário Oficial da União 10 out 1996.

14. Mauro MYC, Paz AF, Mauro CCC, Pinheiro MAS, Silva VG. Condições de trabalho da enfermagem nas enfermarias de um hospital universitário. Esc Anna Nery Rev Enferm 2010;14(2):244-52.

15. Dalri RCMB, Robazzi MLCC, Silva LA. Riscos ocupacionais e alterações de saúde entre trabalhadores de enfermagem brasileiros de unidades de urgência e emergência. Ciencia Enferm(En línea) 2010;XVI (2):69-81, 2010.

16. Feskanich D, Hankinson S, Schernhammer E. Night shift work and fracture risk: the nurses' health study. Osteoporos Int. [periódico na internet]. 2009 [acesso em 7 out 2010];20(4):537-42. Disponível em: http://www.ncbi. nlm.nih.gov/pmc/articles/PMC2651998/?tool = pubmed. 
17. Flôr RC, Kirchhof ALC. Uma prática educativa de sensibilização quanto à exposição a radiação ionizante com profissionais de saúde. Rev Bras Enferm 2006;59(3):274-78.

18. Costa TF, Felli VEA. Periculosidade dos produtos e resíduos químicos da atenção hospitalar. Cogitare Enferm 2012; $17(2): 322-30$.

19. Mirabelli MC, Zock JP, Plana E, Antó JM, Benke G, Blanc PD, et al. Occupational risk factors for asthma among nurses and related healthcare professionals in an international study Occup Environ Med.[periódicona internet]. 2007[acesso em 7 out 2010];64(7):474 79. Disponível em: http://www.ncbi.nlm.nih.gov/pmc/articles/ PMC2078479/? tool = pmcentrez .

20. Cardoso MVLML, Chaves EMC, Bezerra MGA. Ruídos e barulhos na unidade neonatal. Rev Bras Enferm 2010;63(4):561-66. 